\title{
Adsorption Selectivity of Coffee Aroma Components on Zeolite 5A
}

\author{
Tadaaki SAKAnO, ${ }^{1}$ Hajime TAmon, ${ }^{2}$ Minoru Miy Ahara ${ }^{2}$ and Morio OKAZAKI ${ }^{2}$ \\ ${ }^{1}$ Central Research Laboratories, Ajinomoto General Foods Inc., 6410, Minamitamagaki-cho, Suzuka, Mie 513, Japan \\ ${ }^{2}$ Department of Chemical Engineering, Faculty of Engineering, Kyoto University, Yoshida-honmachi, Sakyo-ku, Kyoto 606-01, Japan
}

Received April 16, 1996

\begin{abstract}
For the basic study on removal of methyl mercaptan from coffee volatiles, adsorption characteristics on zeolite 5A were evaluated for 6 model components in a coffee aroma-containing gas. They were methyl mercaptan, acetaldehyde and 2,3-butanedione as aroma components, and nitrogen, carbon dioxide and water as coexisting gas components. Adsorption isotherms for the above components were measured, and heats of adsorption were calculated from the measured isotherms. From the breakthrough curves for binary mixture, the order of adsorption selectivity was determined as water $>$ acetaldehyde $>$ methyl mercaptan $>$ carbon dioxide $>2,3$-butanedione $>$ nitrogen. The order roughly corresponded to the relative order of heats of adsorption. The results suggest that it is necessary to remove water vapor in the aroma-containing gas before the adsorption process for improving the adsorption efficiency of methyl mercaptan. Partial condensation was calculated for a model component system, and it was found that the condensation operation would be useful for the removal of water vapor from an aroma-containing gas.
\end{abstract}

Keywords: adsorption selectivity, coffee aroma, heat of adsorption, methyl mercaptan, zeolite 5A, partial condensation

Volatiles originating from food materials are widely utilized for quality improvement of food products. In the manufacturing of coffee products, aromatized coffee oil that absorbed the volatiles recovered from roasted and ground coffee is added back to liquid coffee extracts or dry products of the extracts as a method of enhancing coffee aroma. Such methods are described in some patents (Lubensen et al., 1973; Siedlecki et al., 1977; Katz et al., 1985). However, the desirable smell in coffee is formed by a delicate balance in the composition of volatiles. Such aromatized oils often have a strongly irritating sulfurous odor. It is therefore advisable to remove such a pungent sulfur-like odor in order to increase consumer acceptability. It is difficult to separate selectively sulfur odor components by means of a distillation or condensation process based on the difference in volatility of the compounds.

An adsorption process has been proposed for quality improvement of coffee aroma evolved from roasted and ground coffee during the commercial extraction process of soluble coffee (Sakano et al., 1996). Zeolite was selected and examined for this purpose because it has a high adsorption selectivity due to the molecular sieving effect and a strong interaction with polar molecules. As the result of the previous study, the adsorption process using an A-type zeolite effectively removed the pungent odor components such as methyl mercaptan identified in the coffee aroma-containing gas. Improvement of the coffee aroma was confirmed by sensory evaluation of the deodorized products. Zeolite $5 \mathrm{~A}$ was most appropriate from the viewpoint of separation efficiency of methyl mercaptan from residual aroma compounds.

The information on the adsorption characteristics of components in the aroma-containing gas is essential to develop an optimum adsorption process. However, adsorption equilibria of coffee aroma on zeolite $5 \mathrm{~A}$ have not been reported in the literature. There are no studies on the influence of the coexisting gases such as carbon dioxide $\left(\mathrm{CO}_{2}\right)$ or water in the aroma-containing gas on the adsorption of coffee aroma components.

The objective of this study is to evaluate the adsorption equilibria and the adsorption selectivity for key coffee aroma components and coexisting gas components on zeolite $5 \mathrm{~A}$ and to evaluate the feasibility of the zeolite adsorption process. Three aroma components and three coexisting gas components were selected as model components of the aroma-containing gas. The adsorption isotherms of these components on zeolite $5 \mathrm{~A}$ were measured. The effects of a coexisting gas on the adsorption of aroma components were also evaluated, and the adsorption selectivity of the model components was then determined.

\section{Materials and Methods}

Adsorbent A commercially available zeolite 5A (Zeolum 5A, spherical, \#8/10, Tosoh Co., Ltd., Tokyo) was used in this work. The micropore structure of the zeolite was determined by nitrogen $\left(\mathrm{N}_{2}\right)$ adsorption at $77 \mathrm{~K}$ with a volumetric adsorption apparatus (BELSORP28, BEL Japan, Inc., Osaka). We used the standard isotherm of $\mathrm{N}_{2}$ on $\mathrm{SiO}_{2}$ and applied the $t$-plot analysis (Mikhail et al., 1968) to the measured isotherm. The physical properties of zeolite $5 \mathrm{~A}$ were obtained as follows: pore volume; $0.228 \times 10^{-3} \mathrm{~m}^{3} / \mathrm{kg}$, specific surface area; $848 \times 10^{3} \mathrm{~m}^{2} / \mathrm{kg}$ and micropore diameter; $0.55 \mathrm{~nm}$.

Preparation of adsorbate gas The model components selected in this work were methyl mercaptan $\left(\mathrm{CH}_{3} \mathrm{SH}\right)$, acetaldehyde $\left(\mathrm{CH}_{3} \mathrm{CHO}\right)$ and 2,3-butanedione $\left(\mathrm{CH}_{3}(\mathrm{CO})_{2}\right.$ - 


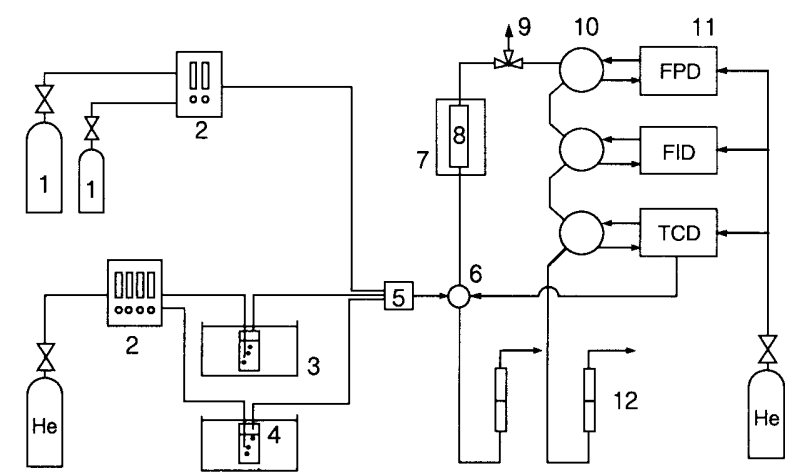

Fig. 1. Experimental apparatus of fixed-bed run. 1, standard gas bomb; 2 , mass-flow controller; 3 , temperature-controlled bath; 4 , bubbling bottle; 5 , mixing unit; 6, 4-way valve; 7 , air oven; 8 , adsorption column; 9 , vent valve; 10 , gas sampling unit; 11, gas chromatograph; 12, soap film meter.

$\mathrm{CH}_{3}$ ) as aroma components, and $\mathrm{N}_{2}, \mathrm{CO}_{2}$ and water as coexisting gas components. Helium ( $\mathrm{He}$ ) was used as an inert carrier gas. $\mathrm{He}, \mathrm{N}_{2}$, and $\mathrm{CO}_{2}$ gases were of high purity grade (>99.99\%). Methyl mercaptan and acetaldehyde that are highly volatile were supplied with $\mathrm{He}(>99.98 \%)$ diluted standard gases at concentrations of 2,910 ppm and 20,400 ppm, respectively. 2,3-Butanedione ( $>98 \%$, Lancaster Synthesis, Morecambe) or distilled water was stored in a sealed glass bottle placed in a temperature-controlled bath. Their saturated vapors were generated by passing $\mathrm{He}$ gas into the liquid in the bottle at constant temperature. The adsorbate gas or vapor was further diluted with He gas to adjust prescribed concentrations.

Experimental Fixed-bed runs were carried out to determine the breakthrough curves of single and binary systems with the experimental apparatus shown in Fig. 1. A stainless steel column (6 mm ID and $10 \mathrm{~cm}$ long) was filled with zeolite $5 \mathrm{~A}$ particles. Before starting the adsorption run, the zeolite was pretreated in He flow at $673 \mathrm{~K}$ for $2 \mathrm{~h}$. By turning a 4-way valve at the beginning of each run, the test gas was introduced to the adsorption column. The gas flow rate was adjusted by a mass-flow controller and measured using a soap film meter.

The inlet and outlet concentrations of the column were measured with three sets of a gas sampling unit and gas chromatograph. Each gas chromatograph was equipped with three different detectors (FID, FPD and TCD). 0.2 or $0.5 \times$ $10^{-6} \mathrm{~m}^{3}$ of the test gas was automatically sampled and injected into each gas chromatograph by an air-actuated sampling valve connected to a time-sequence controller. Each experiment continued until the outlet concentration became the same as that at the inlet, and the equilibrium amount adsorbed was calculated from the breakthrough curve.

The details of the gas chromatograph system were as follows: $\mathrm{CO}_{2}, \mathrm{~N}_{2}$ and water were measured by the TCD detector of a gas chromatograph using a $2.0 \mathrm{~m} \times 3.0 \mathrm{~mm}$ stainless steel column packed with Porapack ${ }^{\circledR} \mathrm{Q}(\# 80 / 100$, Waters Div. of Millipore Co., Milford). The oven temperature was held at $353 \mathrm{~K}$, the injection temperature was $373 \mathrm{~K}$ and that of the detector was $473 \mathrm{~K}$. Acetaldehyde and 2,3butanedione were measured by the FID detector of a gas chromatograph using a $2.1 \mathrm{~m} \times 3.2 \mathrm{~mm}$ glass column packed with Thermon-1000 5\% on Sunpack ${ }^{(\mathbb{B})}$ A (Shinwa Chemical
Table 1. Experimental condition of binary adsorption.

\begin{tabular}{lcr}
\hline Zeolite weight & $0.001 \pm 0.00012$ & {$[\mathrm{~kg}]$} \\
Temperature & $323.2 \pm 0.1$ & {$[\mathrm{~K}]$} \\
Superficial velocity & $0.177 \pm 0.009$ & {$[\mathrm{~m} / \mathrm{s}]$} \\
\hline Coexisting gas component & Feed concentration & {$[$ vol.\%] } \\
\hline Carbon dioxide & $51.06 \pm 0.04$ & \\
Nitrogen & $47.97 \pm 0.02$ & \\
Water & $0.84 \pm 0.01$ & \\
\hline Aroma component & Feed concentration & {$[\mathrm{ppm}]$} \\
\hline Acetaldehyde & $1922 \pm 65$ & \\
Methyl mercaptan & $296 \pm 28$ & \\
2,3-Butanedione & $591 \pm 49$ & \\
\hline
\end{tabular}

Ind., Ltd., Kyoto). The oven temperature was $423 \mathrm{~K}$, and the injector and detector temperatures were at $523 \mathrm{~K}$. Methyl mercaptan was measured by the FPD detector of a gas chromatograph using a $2.1 \mathrm{~m} \times 3.2 \mathrm{~mm}$ glass column packed with PPE-5 rings $10 \%$ on Shimalite ${ }^{\circledR}$ TPA ( $\# 60 / 80$, Shinwa Chemical Ind., Ltd.). The oven temperature was $373 \mathrm{~K}$, and the temperatures of the injection and detector were $423 \mathrm{~K}$. Quantification of each compound was carried out by preparing calibration curves with standard gases and vapors.

Adsorption equilibrium of single components The measurement of a single component isotherm was conducted using two different methods. Adsorption isotherms of 2, 3-butanedione and methyl mercaptan were measured at 303, 323 and $343 \mathrm{~K}$ by fixed-bed adsorption runs. Isotherms of $\mathrm{CO}_{2}$ and $\mathrm{N}_{2}$ at 303,323 and $343 \mathrm{~K}$ and of acetaldehyde and water at 303 and $323 \mathrm{~K}$ were determined with the volumetric adsorption apparatus (BELSORP 18 and 28, BEL Japan, Inc.). Saturated vapor pressure $P_{S}$ for $\mathrm{CO}_{2}$ and $\mathrm{N}_{2}$ was calculated with the Harlacher-Braun equation (Reid et al., 1977) and that for other compounds was estimated by the Antoine equation (Boublik et al., 1984).

Adsorption equilibria of binary components Breakthrough curves of binary components were measured at $323 \mathrm{~K}$ with the fixed-bed apparatus (Fig. 1) to determine the adsorption selectivity. The concentration of each component was prepared similar to the concentration of a coffee aromacontaining gas in an actual plant. The experimental conditions are listed in Table 1.

Heat of adsorption The isotherm data were fitted by a polynomial curve for each temperature. The isosteric heat of adsorption was calculated from the temperature dependence of the fitted curve by the Clausius-Clapeyron equation (Young \& Crowell, 1962).

$$
Q_{i s o}=-R\left[\frac{\partial \ln P}{\partial(1 / T)}\right]_{q}
$$

where $Q_{i s o}=$ isosteric heat of adsorption $[\mathrm{kJ} / \mathrm{mol}], P=$ vapor pressure $[\mathrm{kPa}], T=$ temperature $[\mathrm{K}], q=$ amount adsorbed $[\mathrm{mol} / \mathrm{kg}]$, and $R=$ gas constant $[\mathrm{kJ} / \mathrm{mol} \cdot \mathrm{K}]$.

\section{Results and Discussion}

Adsorption isotherms of single component Adsorption isotherms of methyl mercaptan, acetaldehyde and 2,3-butanedione are shown in Fig. 2. The temperature dependence of the isotherms plotted with the relative pressure $P / P_{S}$ is small for methyl mercaptan. This result suggests that 

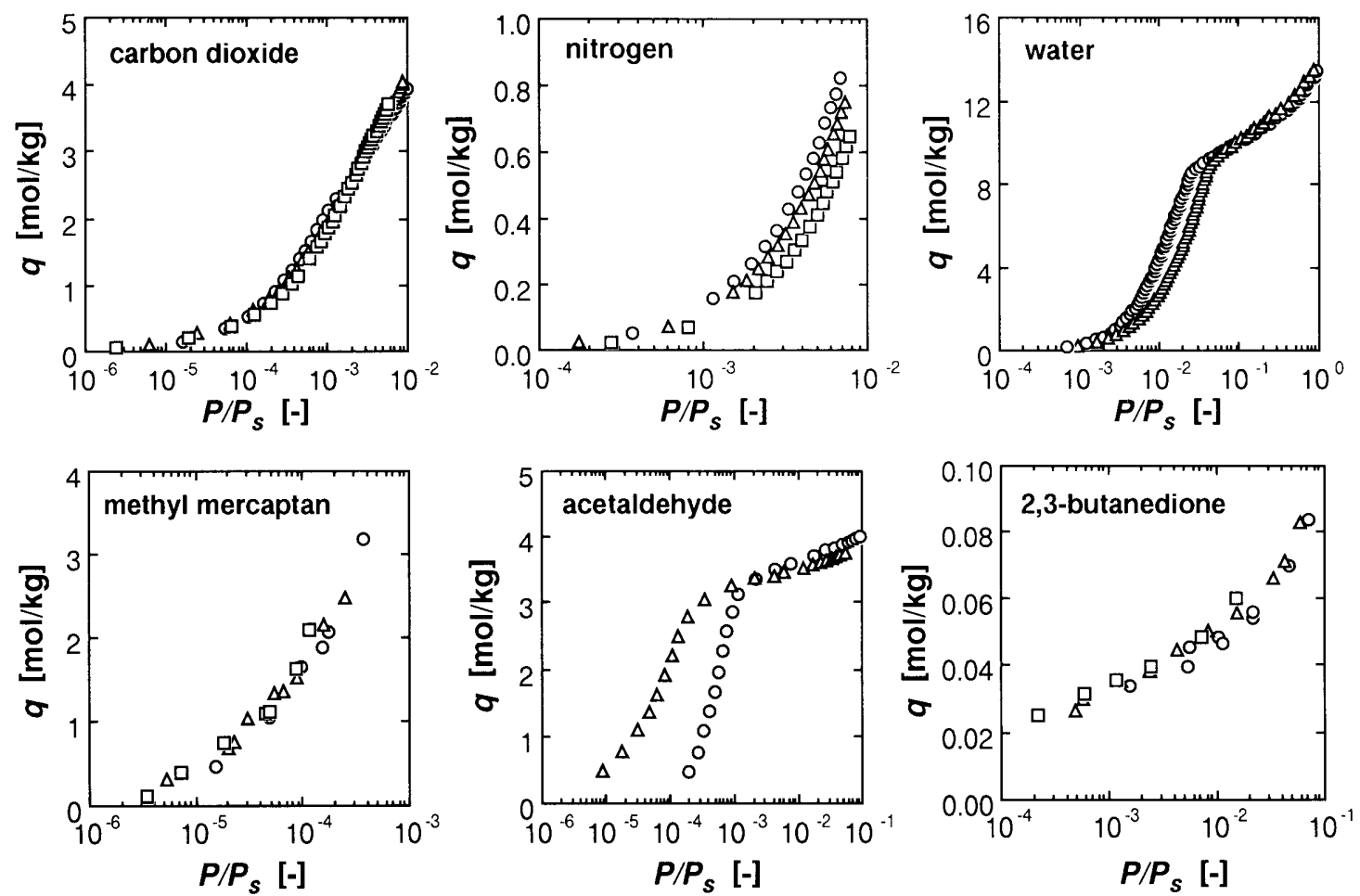

Fig. 2. Adsorption isotherms of model gas components. Adsorption temperature: $303 \mathrm{~K}, \triangle 323 \mathrm{~K}, \square 343 \mathrm{~K}$.

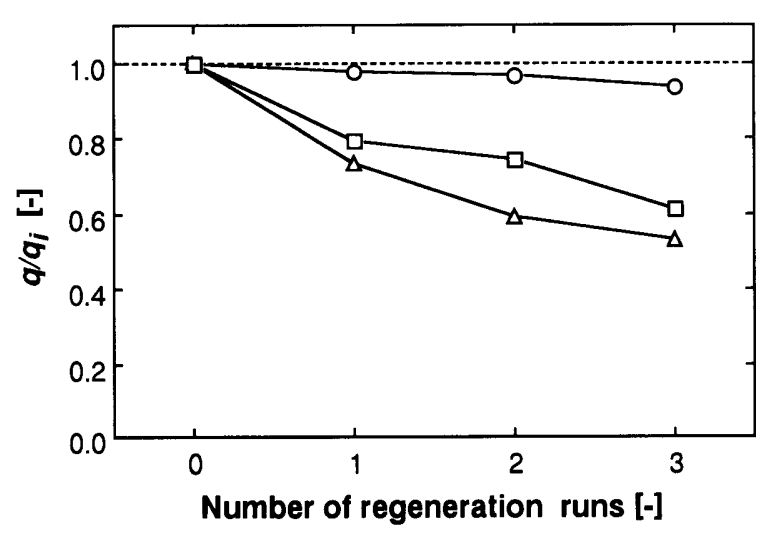

Fig. 3. Change in adsorption amount by repeated regeneration of zeolite $5 \mathrm{~A}$. $q_{i}$ : initial amount adsorbed, $\bigcirc$ water; $q_{i}=6.74 \mathrm{~mol} / \mathrm{kg}, \square 2,3$-butanedione; $q_{i}=$ $0.039 \mathrm{~mol} / \mathrm{kg}, \triangle$ acetaldehyde; $q_{i}=3.05 \mathrm{~mol} / \mathrm{kg}$.

the heat of adsorption would be close to the latent heat and that the interaction between adsorbate and adsorbent would be weak. For acetaldehyde and 2,3-butanedione, in the low relative pressure region, the amounts adsorbed increase with the temperature. The results for these two components suggest that chemisorption may occur on zeolite $5 \mathrm{~A}$. The amount of 2,3-butanedione adsorbed is two orders lower than that of other components. The reason is presumed to be that the molecular size of 2,3-butanedione is larger than the pore diameter of zeolite $5 \mathrm{~A}$.

Identification of chemisorption Repeated regenerations of the zeolites loaded with acetaldehyde, 2,3butanedione or water were performed to examine the appearance of chemisorption. The spent zeolites were regenerated by $\mathrm{He}$ at $673 \mathrm{~K}$. Figure 3 shows the change in amount adsorbed with the regeneration number. The value of $q_{i}$ is the initial

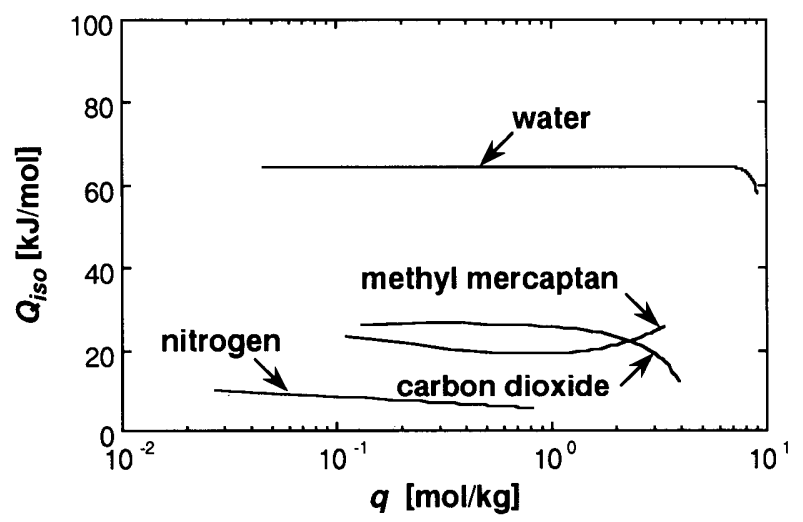

Fig. 4. Isosteric heat of adsorption on zeolite $5 \mathrm{~A}$.

amount adsorbed. The amount of water adsorbed does not change, whereas the amounts of acetaldehyde and 2,3butanedione adsorbed decrease greatly after the first regeneration. The adsorption irreversibility should be caused by chemisorption. This is presumed to be caused by the reaction of the carbonyl group of acetaldehyde or 2,3-butanedione with the hydroxyl group, which acts as an acid catalyst on the zeolite surface (Chavez et al., 1992).

Heat of adsorption It is interesting to estimate the heat of adsorption because it provides directly the strength of the interaction between the adsorbate molecule and the surface of the adsorbent. Figure 4 shows the isosteric heats of adsorption calculated from the fitted curves of isotherm data. Heats of adsorption for both acetaldehyde and 2,3-butanedione have not been calculated because the Clausius-Clapeyron equation is not applicable to chemisorption. The heats of adsorption for the 4 components are nearly independent of the amount adsorbed. Consequently, the relative order of heats of adsorp- 


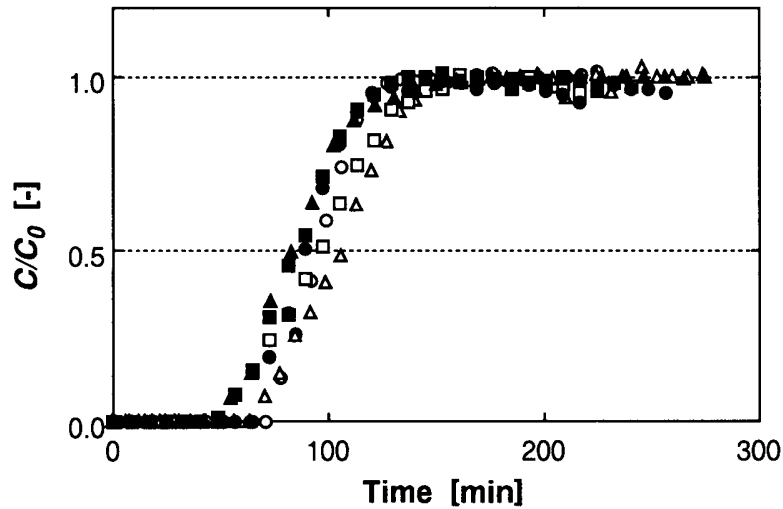

Fig. 5. Breakthrough curves of water in binary system on zeolite $5 \mathrm{~A}$ helium, $\triangle$ nitrogen, $\quad$ carbon dioxide, $\bullet$ methyl mercaptan, $\Delta$ 2,3-butanedione, acetaldehvie.

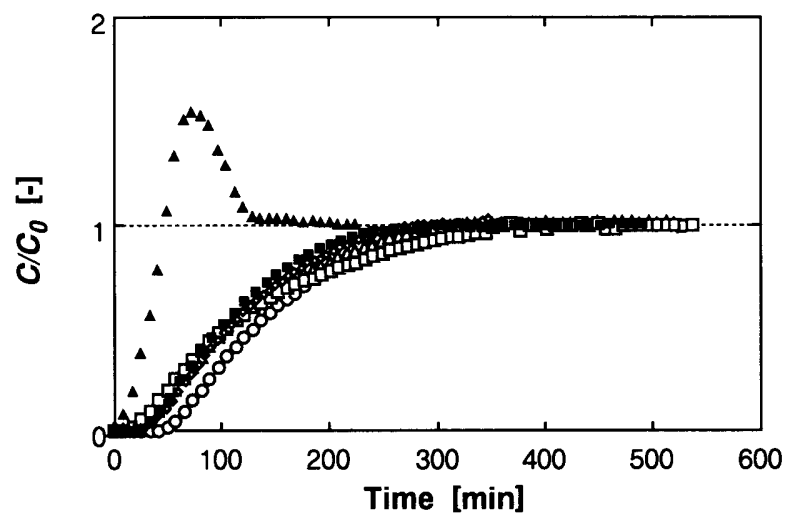

Fig. 6. Breakthrough curves of acetaldehyde in binary system on zeolite $5 \mathrm{~A}$. helium, $\triangle$ nitrogen, $\square$ carbon dioxide, $>2,3$-butanedione, $\square$ methyl mercaptan, $\Delta$ water.

tion for the components is estimated as follows: water $>\mathrm{CO}_{2}$ $\approx$ methyl mercaptan $>\mathrm{N}_{2}$.

Breakthrough curves of binary adsorption Breakthrough curves of binary components were measured to evaluate selectivity based on adsorption kinetics or the molecular sieving effect from the viewpoint of practical separation. The breakthrough curves for water, acetaldehyde and methyl mercaptan in a binary component system are shown in Figs. 5 to 7. Here, the vertical axis represents the relative concentration of outlet gas to the inlet gas. For the reference, the breakthrough curve in the presence of $\mathrm{He}$, which corresponds to the single component breakthrough curve, is also shown in the figures. The breakthrough curves of water (Fig. 5) are almost the same as that of a single component independent of the coexisting components. Thus, water is preferentially adsorbed on zeolite $5 \mathrm{~A}$ and has the strongest adsorptive interaction on the zeolite surface among the model components. The breakthrough curves of acetaldehyde (Fig. 6) are not affected by the coexisting components except water. In the presence of water, acetaldehyde is almost displaced by water. Consequently, acetaldehyde has the second strongest adsorptive interaction next to water.

The breakthrough curves of methyl mercaptan (Fig. 7) are significantly affected by the coexisting components. The order of breakthrough time is water $<$ acetaldehyde $<\mathrm{CO}_{2}<2,3-$ butanedione $<\mathrm{N}_{2}$. Methyl mercaptan is perfectly displaced by water. As shown in Fig. 8, the breakthrough of $\mathrm{CO}_{2}$ was

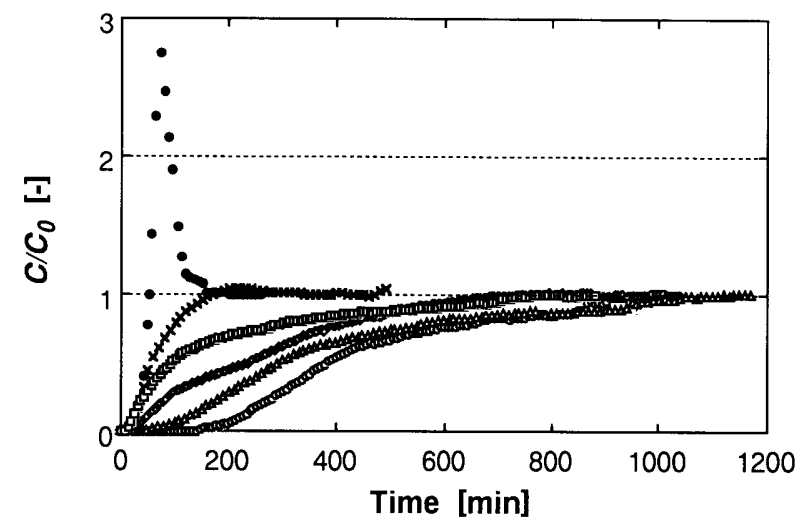

Fig. 7. Breakthrough curves of methyl mercaptan in binary system on zeolite 5A. helium, $\triangle$ nitrogen, I i carbon dioxide, $\times$ acetaldehyde, $\diamond 2,3$ butanedione, $\bullet$ water.

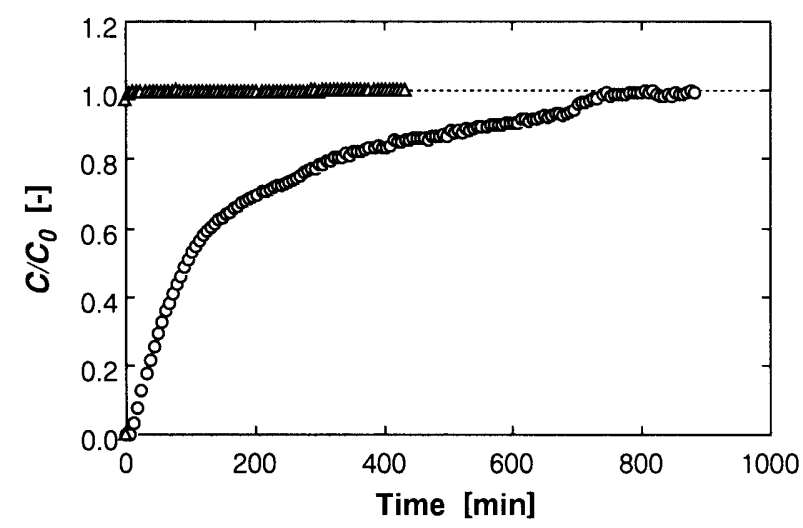

Fig. 8. Breakthrough curves of methyl mercaptan and carbon dioxide in binary system on zeolite $5 \mathrm{~A}$. methyl mercaptan, $\triangle$ carbon dioxide.

much earlier than that of methyl mercaptan in the $\mathrm{CO}_{2}$ methyl mercaptan system.

Consequently, from Figs. 5 to 8, the selective order based on the breakthrough time is determined as water $>$ acetaldehyde $>$ methyl mercaptan $>\mathrm{CO}_{2}>2,3$-butanedione $>\mathrm{N}_{2}$. Water is most selectively adsorbed on zeolite $5 \mathrm{~A}$ and purges acetaldehyde and methyl mercaptan.

Adsorption selectivity To determine the selectivity based on adsorption equilibria among the components used in this work, we calculated the separation factor $S$ defined by the following equation (Ruthven, 1984).

$$
S=\left(X_{i} / Y_{i}\right) /\left(X_{j} / Y_{j}\right)
$$

where $X_{i}$ and $Y_{i}$ are the mole fractions of the $i$ component in the adsorbed and in the gas phases at equilibrium. $X_{i}$ and $Y_{i}$ were determined from the amount adsorbed and the equilibrium concentration obtained in binary adsorption experiments. The value of $S$ is limited by the experimental conditions used because it generally varies with temperature and often also with composition. From the values of $S$ listed in Table 2, the selective order is identified as follows: water $>$ acetaldehyde $>$ methyl mercaptan $>2,3$-butanedione $>\mathrm{CO}_{2}>$ $\mathrm{N}_{2}$. This order is nearly equal to that based on breakthrough time and is roughly equal to the relative order of heats of adsorption. The disagreement in the order of 2,3-butanedione and $\mathrm{CO}_{2}$ seems to be caused by the large difference in those concentrations. Consequently, it appears that the interaction 
Table 2. Separation factor $S$ of aroma component on binary adsorption.

\begin{tabular}{lccc}
\hline Coexisting component & \multicolumn{3}{c}{ Aroma component $(j$ component $)$} \\
\cline { 2 - 4 }$(i$ component $)$ & Methyl mercaptan & Acetaldehyde & 2,3 -Butanedione \\
\hline Water & $\infty$ & 50.3 & 22.8 \\
Nitrogen & $1.21 \times 10^{-3}$ & $4.89 \times 10^{-4}$ & - \\
Carbon dioxide & $2.12 \times 10^{-3}$ & $4.62 \times 10^{-3}$ & - \\
Methyl mercaptan & - & 0.584 & 18.3 \\
Acetaldehyde & 1.65 & - & 21.3 \\
2,3-Butanedione & $5.24 \times 10^{-2}$ & $5.30 \times 10^{-2}$ & -
\end{tabular}

Table 3. Composition of a model aroma-containing gas.

\begin{tabular}{lc}
\hline \multicolumn{1}{c}{ Component } & Composition [vol.\%] \\
\hline Carbon dioxide & 50.00 \\
Nitrogen & 48.52 \\
Water & 0.85 \\
Acetone & 0.40 \\
Acetaldehyde & 0.20 \\
Methyl mercaptan & 0.03 \\
\hline
\end{tabular}

of methyl mercaptan with the zeolite surface is stronger than that of $\mathrm{CO}_{2}$.

Improvement of adsorption efficiency of methyl mercaptan by partial condensation of water It is expected that the adsorption efficiency of methyl mercaptan would be improved if water vapor is removed from an aromacontaining gas before adsorption. We studied the removal of water by partial condensation because methyl mercaptan is more volatile than water. The feed gas is separated into the vapor phase and the liquid/solid phase by condensation. The vapor-liquid equilibria in a multi-component system of condensation were calculated with the process simulation software (ASPEN PLUS ${ }^{\mathrm{TM}}$, Aspen Technology, Inc., Cambridge, USA). Ideal mixtures were assumed and Raoult's law was used for the vapor-liquid equilibrium. Calculations were conducted for a model composition of aroma-containing gas listed in Table 3. Acetone was adopted instead of 2,3butanedione because the physical properties of 2,3butanedione required for calculation were not available. The gas mixture was assumed to be supplied at $278 \mathrm{~K}$.

Figure 9 shows the calculation result for the equilibrium concentration of each component in the vapor phase at various condensation temperatures. $\Phi$ is given by the ratio of the equilibrium concentration in the vapor phase to that in the feed gas. In the condensation at $233 \mathrm{~K}$, for example, the water content in the vapor phase decreases to about $1 / 50$ of the feed gas, that is, water can be removed by condensation. Therefore, in the following adsorption process, the amount of water adsorbed will decrease to about $1 / 30$ from the isotherm data of water. Consequently, this will lead to a significant increase in the adsorption capacity for methyl mercaptan on zeolite $5 \mathrm{~A}$.

The condensate phase contains low volatility aromas and a slight amount of methyl mercaptan with water. Thus, the condensates become finally mixed with the aromas through the adsorption process in order to recover low volatility aromas. Although methyl mercaptan still remains in the condensates, we presume that the final content of methyl mercaptan in the aroma mixture would be lowered to an acceptable level by increasing the amount of methyl mer-

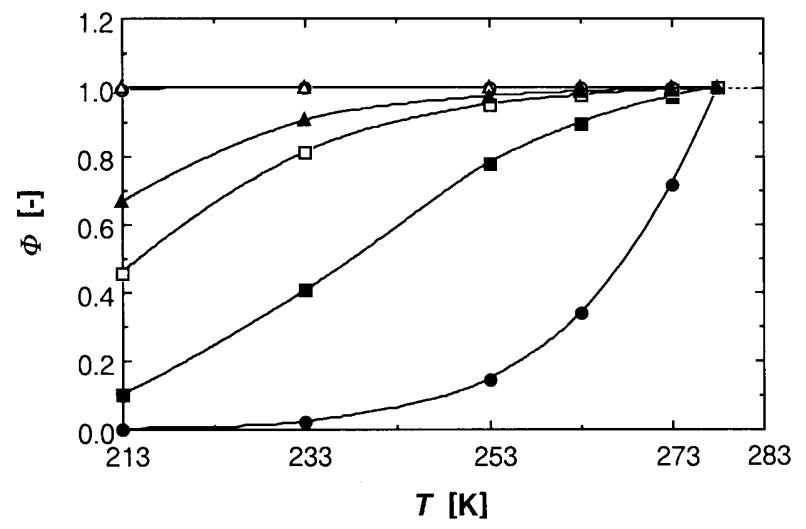

Fig. 9. Retention of aroma-containing gas components in the vapor phase by condensation. $\Phi$ : ratio of equilibrium concentration in vapor phase to feed concentration in condenser. carbon dioxide, $\triangle$ nitrogen, $\Delta$ methyl mercaptan, $-\lrcorner$ acetaldehyde, $\mathbf{\square}$ acetone, $\bullet$ water.

captan adsorbed in the adsorption process to as much as that of the condensed methyl mercaptan. For a commercial application, we have to determine an optimum condensation temperature considering the actual methyl mercaptan content in the condensates. As the conclusion here, it is suggested that the partial condensation of the aroma-containing gas is useful for improving the capacity in the adsorption process.

\section{Conclusions}

The order of adsorption selectivity on zeolite 5A was determined based on the breakthrough time of binary components as follows: water $>$ acetaldehyde $>$ methyl mercaptan $>\mathrm{CO}_{2}>2,3$-butanedione $>\mathrm{N}_{2}$. Among the components physisorbed, $\mathrm{N}_{2}, \mathrm{CO}_{2}$, water and methyl mercaptan, the relative order of the heat of adsorption was roughly equal to that of the adsorption selectivity. The adsorption of methyl mercaptan on zeolite $5 \mathrm{~A}$ was significantly affected by the coexisting components and showed a relatively weak interaction compared with that of acetaldehyde or water. Chemisorption appeared in the adsorption of acetaldehyde and 2,3-butanedione on zeolite $5 \mathrm{~A}$. It was suggested that the condensation of water vapor from the aroma-containing gas before the adsorption process is effective for improving the adsorption efficiency of methyl mercaptan.

\section{Nomenclature}

$C$ : concentration in gas phase

$C_{o}$ : feed concentration in gas phase

$P$ : $\quad$ vapor pressure

$P_{S}: \quad$ saturated vapor pressure

$Q_{i s o}$ : isosteric heat of adsorption

$q$ : amount adsorbed

$q_{i}$ : initial amount adsorbed

$R: \quad$ gas constant

$S: \quad$ separation factor

$T: \quad$ temperature

$X_{i}: \quad$ mole fraction of $i$ component in adsorbed phase [-]

$Y_{i}$ : mole fraction of $i$ component in gas phase $\quad[-]$

$\Phi$ : ratio of equilibrium concentration in vapor phase to that of feed gas in partial condenser $\quad[-]$ 
Acknowledgments The authors wish to thank Messrs. Takahiro Katai and Takashi Azumi for their experimental support. They are also grateful to BEL Japan, Inc. for measuring the adsorption isotherms of water and acetaldehyde on zeolite $5 \mathrm{~A}$

\section{References}

Boublik, T., Fried, V. and Hala, E. (1984). "The Vapor Pressures of Pure Substances, Physical Science Data 17." Elsevier, London.

Chavez Diaz, C.D., Locatelli, S. and Gonzo, E.E. (1992). Acetaldehyde adsorption on HZSM-5 studied by infrared spectroscopy. Zeolites, 12, 851-857.

Katz, S.N., Karney, D.T., Monsey, N.Y. and Bayonrie, N.J. (1985). Method for aromatizing soluble coffee. US Patent 4,556,575. Dec. 3. Lubsen, T.A., Strobel, R.G.K., Reinhart, R.N. and Patel, J.L. (1973). Aroma enriched coffee products and process. US Patent 3,769,032
Oct. 30 .

Mikhail, R.S., Brunauer, S. and Bodor, E.E. (1968). Investigation of a complete pore structure analysis. I. Analysis of micropores. J. Colloid Interface Sci., 26, 45-53.

Reid, R.C., Prausnitz, J.M. and Sherwood, T.K. (1977). "The Properties of Gases and Liquids." 3rd ed. McGraw-Hill, New York.

Ruthven, D.M. (1984). "Principles of Adsorption and Adsorption Process." Wiley-Interscience Publication, New York.

Sakano, T., Yamamura, K., Tamon, H., Miyahara, M. and Okazaki, M. (1996). Improvement of coffee aroma by removing pungent volatiles using A-type zeolite. J. Food Sci., 61, 473-476.

Siedlecki, D.T., Meinhold, J.F., Katz, S.N. and Mahlmann, J.P. (1977) Method of fixing coffee grinder gas. US Patent 4,007,291. Feb. 19. Young, D.M. and Crowell, A.D. (1962). "Physical Adsorption of Gases." Butterworths, London. 